\title{
The future for Howard Hughes
}

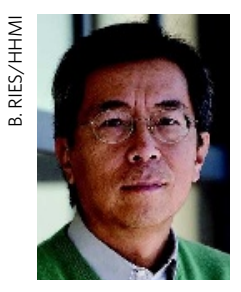

Robert Tjian is a biochemist and molecular biologist at the University of California, Berkeley, who has made significant discoveries about DNA transcription factors. He co-founded the biotechnology company Tularik, which was sold in 2003 for US\$1.3 billion. On 1 April next year, Tjian will take over as president of the privately funded Howard Hughes Medical Institute (HHMI) in Chevy Chase, Maryland. He spoke to Nature about his plans.

\section{What are your priorities for the HHMI?}

The main job is to keep identifying the best people out there who are doing the kind of science that we like - creative, original, somewhat risky - and to give them enough resources to follow their dreams.

\section{Do you want to expand the HHMI's activities in any field?}

Its present direction is already very promising: for example, getting more into chemical engineering, chemistry and bioengineering. We might also look into plant biology and biofuels.

\section{Will the economic crisis affect the HHMI?}

Since 2001, when we had the last downturn, Hughes has become much more adept at dealing with these downturns and upturns. My impression from the board is that their endowment is probably just going to be flat, but not negative.

What is your arrangement with Berkeley? I'll continue to have a lab there, although it'll be pared down. A small portion of my lab may be moved to Janelia Farm on the HHMI campus. But I'm not going to be doing anything with biotech, because the president of the HHMI doesn't do any consulting for companies.

Is Janelia Farm living up to its promise as an interdisciplinary research centre? Janelia was a worthy experiment. We don't know how successful it'll be yet, but it has had a good start and needs time to mature.

\section{Will you try other, similar experiments?} It would be nice if we could do something of that magnitude. I'm optimistic that the economy will eventually improve and our endowment will grow so that more unusual, creative programmes could be discussed.

\section{What are your plans for the HHMI's} education and international programmes? The international programme is terrific in terms of bang for its buck. I will certainly see if we can expand it. Tom [Cech, current HHMI president] went to the HHMI with a very strong vision about education, particularly at the lower levels. I think that's a really difficult nut to crack. I'm more inclined to look at the graduate and upper-division undergraduate opportunities in this country, where I still feel the American education system really shines.

\section{What might this entail?}

For example, technology in the laboratory is changing rapidly, so it would be nice to expose our students to the modern methodology instead of teaching them the same labs we've been teaching them for the past hundred years. Another thing I'd like to do - even though I am a hardcore, reductionist biochemist - is to connect the molecular aspects of biology to really tough problems such as disease. I'm talking about teaching our students to think molecularly but to apply it to human conditions.

\section{What is your management style?}

I enjoy working with people who are fun to work with and who are as intense as I am. I'm still working seven days a week because I like it. I don't consider anything I do as work. I tell my students, I'm not expecting you to come to lab because you're doing work - you come to lab because you're having fun. I come in at weekends not because I think it's an obligation to my work, but because I genuinely enjoy what I do.

\section{What excites you about biology today?}

We're in an epoch of the most rapid growth in the biological sciences: genome sequencing methodologies moving at the speed of light; microfluidics; microscopy advancing at amazing rates; mass spectrometry; systems biology; and computational tools. And there are so many interesting, challenging problems - diagnostics, therapeutics, biofuels, you name it. Interview by Erika Check Hayden.

\section{SNAPSHOT \\ The in silico show}

A motley crew of curvaceous women, cardboard men and other avatars gathered last Thursday on Nature's island in Second Life. The occasion for this virtual world get-together was the premiere of Missions in Space-Time, a five-part documentary series produced by Nature Video.

The films capture conversations between young researchers and Nobel prizewinning physicists at the 2008 Nobel Laureate Meeting on Lindau Island in Germany. The first instalment discusses hopes and dreams for the Large Hadron Collider - the particle accelerator at CERN, Europe's particle-physics laboratory near Geneva in Switzerland.

Part one is available for download now; subsequent instalments will be released weekly via iTunes and online at www.nature.com/video/lindau.

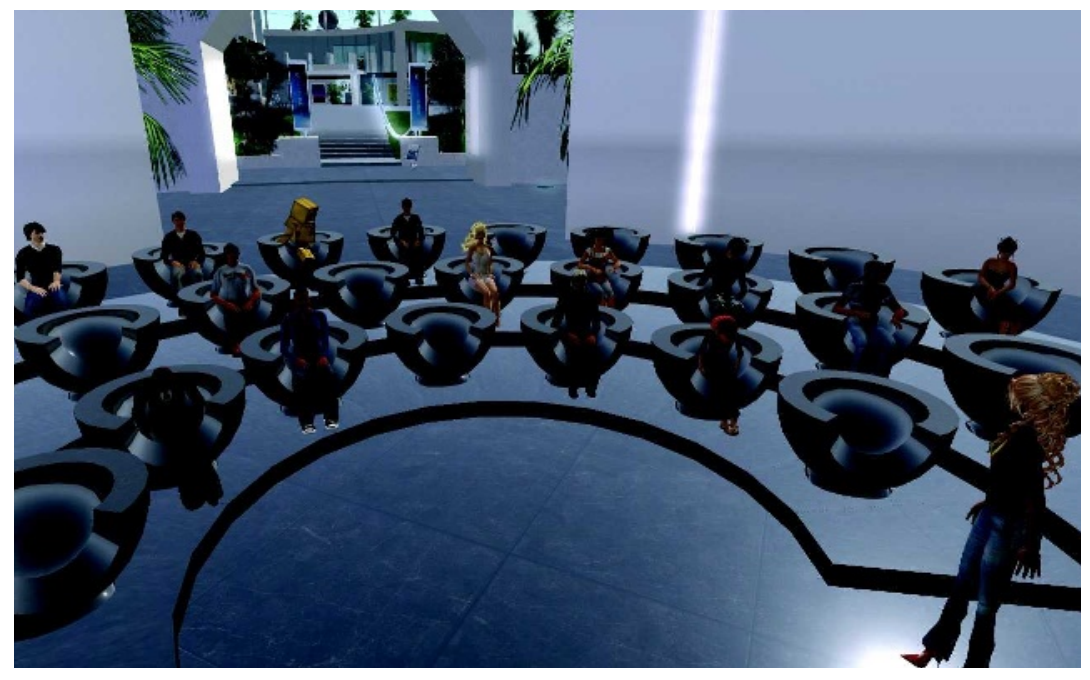

